\title{
Study on the nature of impurities in the circulating glycol solution at the installation of gas purification from acidic components
}

\author{
(C) Tatiana A. Kuryakova, ${ }^{*+}$ and Natalia G. Beregovaya \\ Department of Chemical Technology and Processing of Hydrocarbons and Ecology. \\ Russian State University of Oil and Gas Named after I.M. Gubkin. Young Lenintsev St., 20. \\ Branch in Orenburg. Orenburg, 460047. Orenburg Region. Russia. \\ Phone:+7 (903)36-69-69.E-mail: tany_kur1975@mail.ru
} \begin{abstract}
Keywords: natural gas, dewatering, gas purification, monoethylene glycol, amine process.
\end{abstract}
*Supervising author; ${ }^{+}$Corresponding author

\begin{abstract}
Natural gas contains a large amount of moisture, which causes a lot of problems in its transportation and processing. In order to extract this moisture, natural gas gets subjected to the dewatering process, thereby reducing the moisture content and preventing further formation of hydrates. This is achieved by cleaning the gas from hydrogen sulfide and mercaptans and cooling in heat exchangers with the participation of a solution of monoethylene glycol.

Together with gas, impurities come in the form of hydrocarbons, brine water, mechanical impurities, corrosion inhibitors, various SASs, resinous substances, etc. As a result of deposition of unwanted impurities on the internal surfaces of devices, the efficiency of mass exchange and heat exchange processes is reduced, equipment wear is increased, so is the laborious process of cleaning equipment during planned repairs, the temperature of the glycol block is disrupted and, as a result, the reagent consumption increases in order to maintain the necessary dewatering temperature of natural gas, and the waste of the glycol from the regeneration apparatus increases.

The object of the study was the regeneration block of the saturated solution of monoethylene glycol. During the planned repairs of the plant, there was revealed significant contamination of the devices and heat exchange equipment of the glycol regeneration unit with a large number of unwanted impurities and sediments, as well as significant corrosion of pipe beams of heat exchangers and internal cavity of devices.

We found that the most effective ways to prevent sediment formation in the monoethylene glycol regeneration unit are to better control the level of amine in the 374 B09 devices, to control the consumption of the amount of monoethylene glycol injected into heat exchangers, and to reduce the amount of impurities in the circulating solution of monoethylene glycol. Also, to reduce sediments in the heat exchange apparatus of the gas dewatering section, we recommend increasing the separation rate by installing jack elements in the 374 B09 separator and installing an additional filter in accordance with the proposed scheme, with a cartridge of polyphenylsulfide or fiberglass.
\end{abstract}

\section{References}

[1] Yu.F. Makogon. Natural gas hydrates: distribution, formation models, resources. Russian chemical journal. 2003. Vol.48. No.3. P.70-79. (russian)

[2] Technology regulations of the installation 1,2,3U-370 of Orenburg GPP. (russian)

[3] N.V. Busygina, I.G. Busygin. Processing technology of natural gas and gas condensate. Orenburg: Gazprompechat. 2002. 432p. (russian)

[4] S.N. Kolokoltsev. Improving technologies of hydrocarbon gas preparation and processing. St. Petersburg: Lenand. 2015. 600p. (russian)

[5] T.A. Kuryakova, E.A. Faizova, G.E. Starova. Environmental safety: challenges and solutions. Environmental responsibility of oil and gas companies: Conference proceedings. Orenburg. 2017. P.154159. (russian)

[6] G.K. Zibert, A.D. Sedykh, et al. Preparation and processing of hydrocarbon gases and condensates. Technology and equipment: Reference manual. Moscow: OJSC Nedra-Business Center. 2001. 316p. (russian)

[7] T.V. Bukharkina, et al. Chemistry of natural energy carriers and carbon materials: a tutorial. Moscow: Technika Publishing House, TUMA GROUP. 2009. 204p. (russian) 
[8] T.A. Kuryakova, L.V. Mezhueva, A.V. Bykov, V.P. Popov, A.V. Berestova. Selection of a technological mode to reduce salts and water in the product oil of Orenburg and Kopansk oil-gas condensate fields. Research journal of pharmaceutical, biological and chemical sciences. 2019. Vol.10. No.2. P.1291-1296. (russian)

[9] A.K. Manovyan. Oil and natural gas primary processing technology: A textbook for universities. 2nd ed. Moscow: Chemistry. 2001. 568p. (russian)

[10] T.L. Lukanina, I.S. Mikhailova, M.A. Radin. Chemical resistance of materials and protection from corrosion: a tutorial. St. Petersburg: St. Petersburgb STUPP. 2014. 85p. (russian)

[11] T.M. Bekirov. The impact of the reservoir parameters of the field on the operation of gas processing plants. Preparation and processing of gas and gas condensate. 1983. No.1. P.1-3. (russian)

[12] T.A. Kuryakova, S.G. Bezryadin, E.Yu. Klyukvina, and L.V. Mezhueva. Research of emulsion properties of oil with selection of effective chemical reagents for destruction of arising emulsions. Butlerov Communications. 2019. Vol.60. No.12. P.110-115. DOI: 10.37952/ROI-jbc-01/19-60-12-110

[13] A.G. Sardanashvili, A.I. Lvova. Examples and tasks on oil and gas processing technology. Moscow: Chemistry. 1973. 256p. (russian)

[14] A.A. Kuznetsov, E.N. Sudakov. Calculations of processes and facilities of the oil-refining industry. Leningrad: Chemistry. 1974. 337p. (russian) 